\title{
Ultraviolet-C Light Effect on the Physicochemical and Antioxidant Properties of Blackberry, Blueberry, and Raspberry Nectars
}

\author{
José Fernando Haro-Maza ${ }^{1} \&$ José Ángel Guerrero-Beltrán ${ }^{1}$ \\ ${ }^{1}$ Departamento de Ingeniería Química, Alimentos y Ambiental. Universidad de las Américas Puebla. Ex Hda. \\ Santa Catarina Mártir, San Andrés Cholula, Puebla 72810, Mexico \\ Correspondance: José Ángel Guerrero-Beltrán, Departamento de Ingeniería Química, Alimentos y Ambiental. \\ Universidad de las Américas Puebla. Ex Hda. Santa Catarina Mártir, San Andrés Cholula, Puebla 72810, Mexico. \\ Tel.: 52-222-229-2126. E-mail: angel.guerrero@udlap.mx; joseangel150@hotmail.com
}

Received: June 28, 2016

Accepted: July 14, 2016 Online Published: August 21, 2016

doi:10.5539/jfr.v5n5p11

URL: http://dx.doi.org/10.5539/jfr.v5n5p11

\begin{abstract}
The effect of UV-C light on foodborne microorganisms (mesophilic aerobic bacteria (MAB), molds, and yeasts), physicochemical characteristics (color, total soluble solids, $\mathrm{pH}$, and acidity), and antioxidant properties (ascorbic acid, antioxidant capacity (AC), total monomeric anthocyanins (TMA), and total phenolic compounds (TPC)) in blackberry, blueberry, and raspberry nectars was evaluated. Nectars were UV-C light treated at five times $(5,10$, 15,20 , and 25 minutes) at constant flow rate $(16.48 \mathrm{~mL} / \mathrm{s})$. The best UV-C light treatment for the three nectars, from the microbiological point of view, was $25 \mathrm{~min}$. A statistical difference $(\mathrm{p}<0.05)$ in TPC, within treatment times, was observed in nectars; their content was reduced as the treatment time increased, except for the blackberry nectar. The same effect was observed for the antioxidant capacity. The TMA content increased with the UV-C light treatment.
\end{abstract}

Keywords: UV-C light, blueberry, raspberry, blackberry, antioxidants

\section{Introduction}

Minimal processed foods is a tendency that has been growing in recent years due to a genuine consumer concern about their health and the effects some food additives might have on them. The production of foods is focusing toward obtaining high nutritional and minimal processed products, a good example of these types of foods are berries nectars, which are high in nutritional value: antioxidant compounds, vitamins and minerals; they can be minimally processed. To gather these criteria of safety and minimal processing some emerging technologies have been implemented, most of them are still being investigated to guarantee their reliability and affectivity. The main objective for using nonthermal processing technologies consists in replacing chemicals and thermal sterilization methods to achieve an adequate microbiological reduction and minimize the effect on the nutritional and sensorial properties of the manufactured foods (Alothman, Bhay, \& Karim, 2009).

The UV-C light processing offers a valuable alternative for processing foods. The use of this technology is well established in cases of water, surface and air disinfection; however, its use in food products, including fruit nectars, is still under investigation and its diffusion as a promising alternative to heat treatments is still limited. Thus, UV-C light technology has a wide potential to be developed for its industrial implementation; it can be used in peeled sliced fruits, liquid products, and fresh vegetables (Ribeiro, Canada, \& Alvarenga, 2012) because of its high affectivity for inhibiting bacteria and other types of microorganisms.

UV-C light affects microorganisms at DNA level causing mutations due to the separation of the double helix, avoiding in this way their replication (Gardner and Shama, 2000). Another favorable aspect of the UV-C light implementation comes with the approval from the Food and Drug Administration (FDA, 2000); this organization approved its use as an alternative for fruit juices pasteurization. In the same year, the United States Department of Agriculture (USDA) approved this technology and its use in food products.

The objective of this study was to evaluate the effect of UV-C light on microorganisms and on the physicochemical and antioxidant properties of blackberry, blueberry, and raspberry nectars. 


\section{Method}

\subsection{Nectar Preparation}

Frozen berries (Global premier®), packed in Chicago, Illinois, were homogenized using an immersion food processor (Oster, Mod. 2609 - B2609, Tlalnepantla, Edo de México), filtered through a stainless steel kitchen strainer, and then passed through cheese cloth several times for eliminating coarse fruit particles, resulting in 100\% pulp free juices. Juices were analyzed in $\mathrm{pH}$ (Orion $\mathrm{pH}$ meter, Thermo Scientific, Waltham, MA, USA) and total soluble solids (TSS) (Atago refractometer, Osaka, Japan). Separately, a sucrose syrup (containing the same TSS of fruit juices) was prepared and $\mathrm{pH}$ adjusted (similar to the fruit $\mathrm{pH}$ ). Nectars were prepared mixing 50\% of fresh fruit juice and 50\% of syrup. Nectars were immediately analyzed and UV-C light processed.

\subsection{UV-C Light Processing}

Berries nectars were processed in a UV-C light system, similar to a double wall heat exchanger, assembled at the Universidad de las Americas Puebla (Guerrero-Beltrán and Barbosa-Cánovas, 2006; Guerrero-Beltrán, Welti-Chanes, \& Barbosa-Cánovas, 2009). The external wall was made of stainless steel with an internal diameter of $4.8 \mathrm{~cm}$. The inner wall was a quartz tube with an external diameter of $2.2 \mathrm{~cm}$. The gap by which liquid flew was $2.6 \mathrm{~cm}$. The UV-C light lamp was hosted in the center of the system, surrounded by the annular part (chamber) by where the liquid product was passed through. The UV-C mercury lamp (Orange, Connecticut, USA), used as the light source, was 303 and $15 \mathrm{~mm}$ in length and diameter, respectively, and had an intensity of $17 \mathrm{~W}$ that deliver a dosage of $57 \mu \mathrm{W} / \mathrm{cm}^{2}$. The chamber of the system host a volume of $430 \mathrm{~mL}$. In order to process the fluid $(600 \mathrm{~mL})$, this was passed through the chamber at $4^{\circ} \mathrm{C}$ using a recirculating chilling unit model DC50-B12 (Haake instruments, Germany). The nectar was pumped through the UV-C light system and recirculated, using a peristaltic pump model 75553-7 (Master Flex, Vernon, Illinois, USA), at a constant flow rate of $16.48 \mathrm{~mL} / \mathrm{s}(0.989 \mathrm{~L} / \mathrm{min}$ ) (Ochoa-Velasco \& Guerrero-Beltrán, 2012). Nectars were UV-C light processed during $5,10,15,20$, and 25 min corresponding to doses (D) of $0.171,0.342,0.513,0.684$, and 0.860 $\mathrm{kJ} / \mathrm{m}^{2}$, respectively (Guerrero-Beltrán \& Barbosa-Cánovas, 2006). Untreated nectars were used as a reference for comparison purposes. The UV-C light treatment was performed in duplicate and each method in triplicate. Control and processed nectars were analyzed in physicochemical, microbiological, and antioxidant characteristics. The residence time $(\theta=26.10 \mathrm{~s})$ was obtained dividing the volume of the chamber $(\mathrm{V}=430 \mathrm{~mL})$ per the flow rate $(\mathrm{q}=16.48 \mathrm{~mL} / \mathrm{s})$. The number of passes $(\mathrm{NP}=\mathrm{t} / \theta)$, at each processing time $(\mathrm{t})$, were 11.50 , 23.00, 34.49, 45.99, and 57.48, respectively (Guerrero-Beltrán \& Barbosa-Cánovas, 2006).

\subsection{Physicochemical Analysis}

Acidity. The acidity (\% p/v as citric acid) was performed according to the 942.15 AOAC (2000) method.

$\mathrm{pH}$. A previously calibrated (buffers 4, 7 and 10) digital $\mathrm{pH}$ meter (Jenway, Lansing, USA) was used for measuring $\mathrm{pH}$ of nectars.

TSS $\left({ }^{\circ} \mathrm{Bx}\right)$. TSS content was performed using a manual ATAGO refractometer (Osaka, Japan).

\subsection{Color}

The color was measured using a Colorgard System/05® colorimeter (Gardener, Geretsried, Germany) in the CIELAB (Commission Internationale d'Eclairage $L^{*}, a^{*}, b^{*}$ ) scale for measuring $L^{*}, a^{*}$ and $b^{*}$ color parameters in the transmittance mode. For each assay, $4 \mathrm{~mL}$ of sample were used. The total change in color $(\Delta \mathrm{E})$ was calculated according to McLaren (1986).

\subsection{Antioxidant Analysis}

Antioxidant capacity. The nectars antioxidant capacity was analyzed according to the Kuskoski, Asuero, Parrilla, Troncoso, \& Fett (2004) method with some modifications. The $\mathrm{ABTS}^{+}$radical was obtained mixing $5 \mathrm{~mL}$ of distillated water, $3.3 \mathrm{mg}$ of potassium persulfate, and $19.4 \mathrm{mg}$ of ABTS reagent; the mixture was left to stand in the dark at $25^{\circ} \mathrm{C}$ for 16 hours. After that, pure ethanol was used to dilute the $\mathrm{ABTS}^{+}$radical (radical solution) until reaching an absorbance of $0.70 \pm 0.02$ at $754 \mathrm{~nm}$. Then $80 \mu \mathrm{L}$ of nectar were mixed with $3920 \mu \mathrm{L}$ of ABTS radical solution, blended, and the initial absorbance $(A i)$ measured. After 7 minutes or reaction, the final absorbance $\left(A_{f}\right)$ was measured. The antioxidant capacity was calculated using a standard curve of Trolox $(\mathrm{T})$ with the following equations:

$$
U I=\frac{A_{i}-A_{f}}{A_{i}} * 100
$$




$$
U T=\frac{U I-b}{m} * 100
$$

where $U I$ is the inhibition $(\%), U T$ is the amount of Trolox $(\mathrm{mg} \mathrm{T} / \mathrm{mL}), b$ is the intercept, and $m$ is the slope $(\mathrm{mL} / \mathrm{mg}$ Trolox $)$. The standard curve $(0$ to $0.2 \mathrm{mg}$ Trolox $/ \mathrm{mL})$ was: Abs $=490.40 \mathrm{~mL} / \mathrm{mg} *[\mathrm{mg} / \mathrm{mL}]+3.16\left(\mathrm{R}^{2}=\right.$ 0.981).

Total phenolic compounds (TPC). They were analyzed according to the Gao, Ohlander, Jeppsson, Bjork, \& Trajkovski (2000) method with some modifications. Two milliliters of distillated water were placed in an amber glass tube, then $200 \mu \mathrm{L}$ of Folin and Ciocalteu reagent (Sigma-Aldrich, Toluca, Mexico), $100 \mu \mathrm{L}$ of diluted sample and $1 \mathrm{~mL}$ of a $20 \%(\mathrm{w} / \mathrm{v}) \mathrm{Na}^{2} \mathrm{CO}^{3}$ were added and totally mixed. Samples were left in the dark at room temperature for an hour. The absorbance was measured at $675 \mathrm{~nm}$ using an UNICO UV-Vis spectrophotometer model $2800 \mathrm{H}$ (NJ, USA). The phenolic compounds calculation was performed using a standard curve of Gallic acid ( 0 to $0.3 \mathrm{mg} / \mathrm{mL})$ and the next equation:

$$
G A=\left(\frac{A-b}{m}\right) * 100
$$

where $G A$ is the Gallic acid content ( $\mathrm{mg}$ of Gallic acid/100 mL), $A$ is the sample absorbance, $b$ is the intercept, and $m$ is the slope (mL/mg GA). The standard curve was: Abs $=3.563 \mathrm{~mL} / \mathrm{mg} *[\mathrm{mg} / \mathrm{mL}]+0.053\left(\mathrm{R}^{2}=0.971\right)$.

Total monomeric anthocyanins (TMA). The TMA content was performed according to the Giusti \& Wrolstad (2000) method. It is based in the structural transformations of anthocyanins due to the formation of the flavilio cation at $\mathrm{pH} 1$ and its colorless form at $\mathrm{pH} 4.5$.

Ascorbic acid. The ascorbic acid content was analyzed using the 967.21 AOAC (2000) method.

\subsection{Microbial Counts}

The mesophilic aerobic bacteria (MAB) as well as molds plus yeasts were evaluated using the standard plate count agar and potato dextrose acidified agar (with $10 \%$ tartaric acid) methods, respectively. Cultures in Petri dishes were incubated at $35 \pm 2$ and $25 \pm 2{ }^{\circ} \mathrm{C}$, respectively, for counting colonies forming units per milliliters (CFU/mL) after 2 and 5 days, respectively.

\subsection{Statistical Methods}

A Microsoft Excel program was used for calculating means and standard deviations. ANOVA and Tukey's test data were calculated using the MINITAB 16 program for determining significant differences among means at a confidence level of 0.05 .

\section{Results and Discussion}

\subsection{Physicochemical Analysis}

Acidity. Table 1 shows the acidity of control and UV-C light treated nectars. Even though significant differences $(\mathrm{p}<0.05)$ were found among some exposition times, they are not directly related to the treatment time. No direct relationship between treatment time and acidity changes was found. In general, it can be said that the treatment time did not affect the acidity of berry nectars. Also, there is no information in the literature that could indicate the opposite. Berries fruits are acid products due to the presence of organic acids; however, the acid content can change depending on factors such as the fruit type and season of production.

Table 1. Effect of UV-C light on acidity of nectars of berries.

\begin{tabular}{llll}
\hline \multicolumn{4}{c}{ Acidity $(\mathrm{g} / 100 \mathrm{~mL})$} \\
\hline Time (min) & Blueberry & Raspberry & Blackberry \\
\hline 0 & $0.22 \pm 0.00 \mathrm{ab}$ & $0.69 \pm 0.03 \mathrm{~b}$ & $0.62 \pm 0.00 \mathrm{a}$ \\
5 & $0.20 \pm 0.00 \mathrm{c}$ & $0.82 \pm 0.02 \mathrm{a}$ & $0.61 \pm 0.01 \mathrm{~b}$ \\
10 & $0.21 \pm 0.01 \mathrm{bc}$ & $0.63 \pm 0.00 \mathrm{~b}$ & $0.57 \pm 0.02 \mathrm{~d}$ \\
15 & $0.23 \pm 0.01 \mathrm{a}$ & $0.67 \pm 0.01 \mathrm{~b}$ & $0.60 \pm 0.00 \mathrm{c}$ \\
20 & $0.22 \pm 0.00 \mathrm{ab}$ & $0.67 \pm 0.01 \mathrm{~b}$ & $0.61 \pm 0.00 \mathrm{~b}$ \\
25 & $0.23 \pm 0.00 \mathrm{a}$ & $0.65 \pm 0.01 \mathrm{~b}$ & $0.60 \pm 0.00 \mathrm{c}$
\end{tabular}

Different letters in same column indicate significant differences $(\mathrm{p}<0.05)$ within treatment times. 
$\mathrm{pH}$. Table 2 shows $\mathrm{pH}$ of control and UV-C light treated nectars. It can be observed, that there is not sufficient evidence $(\mathrm{p}>0.05)$ to indicate that the UV-C light treatment affected the $\mathrm{pH}$ of nectars. The $\mathrm{pH}$ values reported by Purgar, Duralija, Voca, Vokurka, \& Ericisli (2012) for blackberry and raspberry are similar to those obtained in this study. They pointed out that berries juices, including blueberry, have a $\mathrm{pH}$ between 3.1 and 3.7, depending on the season of production.

Table 2. Effect of UV-C light on pH of nectars of berries.

\begin{tabular}{llll}
\hline \multicolumn{4}{c}{$\mathrm{pH}$} \\
\hline Time (min) & Blueberry & Raspberry & Blackberry \\
\hline 0 & $3.30 \pm 0.00 \mathrm{a}$ & $3.10 \pm 0.05 \mathrm{a}$ & $3.31 \pm 0.00 \mathrm{a}$ \\
5 & $3.29 \pm 0.00 \mathrm{a}$ & $3.10 \pm 0.02 \mathrm{a}$ & $3.32 \pm 0.00 \mathrm{a}$ \\
10 & $3.30 \pm 0.01 \mathrm{a}$ & $3.14 \pm 0.02 \mathrm{a}$ & $3.32 \pm 0.00 \mathrm{a}$ \\
15 & $3.30 \pm 0.00 \mathrm{a}$ & $3.14 \pm 0.02 \mathrm{a}$ & $3.32 \pm 0.00 \mathrm{a}$ \\
20 & $3.29 \pm 0.00 \mathrm{a}$ & $3.13 \pm 0.02 \mathrm{a}$ & $3.30 \pm 0.01 \mathrm{a}$ \\
25 & $3.29 \pm 0.00 \mathrm{a}$ & $3.15 \pm 0.02 \mathrm{a}$ & $3.30 \pm 0.02 \mathrm{a}$ \\
\hline
\end{tabular}

Different letters in same column indicate significant differences $(\mathrm{p}<0.05)$ within treatment times.

Total soluble solids. TSS remained barely constant along the UV-C light treatment (Table 3). Natural berries juices have TSS between 9.0 and 11.8\% (Purgar, Duralija, Voca, Vokurka, \& Ericisli, 2012), most of them being sugars and organic acids; this is why nectars still have some sour taste. After performing the statistical analysis, significant differences were found $(\mathrm{p}<0.05)$ for total soluble solids within treatment time of nectars; however, an actual tendency of increasing or decreasing of total soluble solids is not observed; therefore, this effect could be associated to experimental measurement.

Table 3. Effect of UV-C light on total soluble solids of nectars of berries.

\begin{tabular}{llll}
\hline \multicolumn{4}{c}{ Total soluble solids $(\mathrm{g} / 100 \mathrm{~g})$} \\
\hline Time (min) & Blueberry & Raspberry & Blackberry \\
\hline 0 & $10.86 \pm 0.05 \mathrm{ab}$ & $8.90 \pm 0.14 \mathrm{ab}$ & $9.10 \pm 0.00 \mathrm{a}$ \\
5 & $10.96 \pm 0.05 \mathrm{ab}$ & $8.83 \pm 0.24 \mathrm{ab}$ & $9.10 \pm 0.00 \mathrm{a}$ \\
10 & $11.03 \pm 0.05 \mathrm{a}$ & $8.66 \pm 0.24 \mathrm{~b}$ & $9.10 \pm 0.00 \mathrm{a}$ \\
15 & $10.83 \pm 0.05 \mathrm{~b}$ & $8.60 \pm 0.29 \mathrm{~b}$ & $9.10 \pm 0.00 \mathrm{a}$ \\
20 & $10.86 \pm 0.12 \mathrm{ab}$ & $9.16 \pm 0.24 \mathrm{a}$ & $9.10 \pm 0.00 \mathrm{a}$ \\
25 & $10.83 \pm 0.12 \mathrm{~b}$ & $9.16 \pm 0.24 \mathrm{a}$ & $9.10 \pm 0.00 \mathrm{a}$ \\
\hline
\end{tabular}

Different letters in same column indicate significant differences $(\mathrm{p}<0.05)$ within treatment times.

\subsection{Color}

In general, nectars were turbid with pale reddish (raspberry), purplish (blackberry), or bluish (blueberry) colors.

$L^{*}$ color parameter. Figure 1 illustrates the UV-C light treatment time effect on the $L^{*}$ color parameter of berries nectars. The $L^{*}$ color parameter refers to the sample lightness; it has values from 0 (perfect black) to 100 (perfect white). Blueberry nectar had an $L^{*}$ value of 38.28 at time 0 , after five minutes of UV-C light treatment the $L^{*}$ value increased and this was changing along the treatment time until reaching a value of 38.45 after 25 min; however, those changes are due to other factors such as particles in the nectar because the tendency is not constant; this means that the $L^{*}$ color parameter do not goes down or up constantly. The initial and final $L^{*}$ values were similar. This means that the dark color remained almost constant along the UV-C light treatment. Raspberry nectar was the less dark of the three nectars; it had a similar tendency as blueberry nectar during treatment regarding the $L^{*}$ color parameter; its lightness increased after 5 minutes of treatment from 44.54 to 48.26 and reached a final value of 43.38 after 25 minutes; similar to the initial lightness. Blackberry nectar decreased in lightness after UV-C light treatment; however, the final $L^{*}$ value was barely greater than the initial $L^{*}$ value of nectar without UV-C light treatment, time 0 . It should take into account that the scale in Figure 1 is very expanded. According to Guerrero-Beltrán, Welti-Chanes, \& Barbosa-Cánovas (2009), lightness in some liquid foods has greater changes when the volumetric flow in the UV-C light process is lower than $1.21 \mathrm{~mL} / \mathrm{s}$; however, as flows increases the $L^{*}$ parameter of liquid foods may barely change during UV-C light treatments. 
In some cases, if the processing time is prolonged the $L^{*}$ color parameter may increase (fading of color), depending of the color of the product. This is not the case in this study, since only one flow rate was used (16.48 $\mathrm{mL} / \mathrm{s}$ ). According to other UV-C light studies in fruit juices, lightness may change (the $L^{*}$ value may increase) as the treatment time increases (Guerrero-Beltrán, Welti-Chanes, \& Barbosa-Cánovas, 2009). These authors also found that after 30 minutes of UV-C light treatment the lightness values of juices were very close to the initial values at time 0 (no treated). According to the statistical analysis, there was no significant differences $(\mathrm{p}>0.05)$ for $L^{*}$ values within treatment times ( 0 to 25 minutes); thus, this shows that the UV-C light treatment does not affect the lightness of these three berries nectars. The three types of nectars have anthocyanins that make them red-purple-blue in color; therefore, UV-C light may affect this types of food pigments (Fulecki \& Francis, 1968).

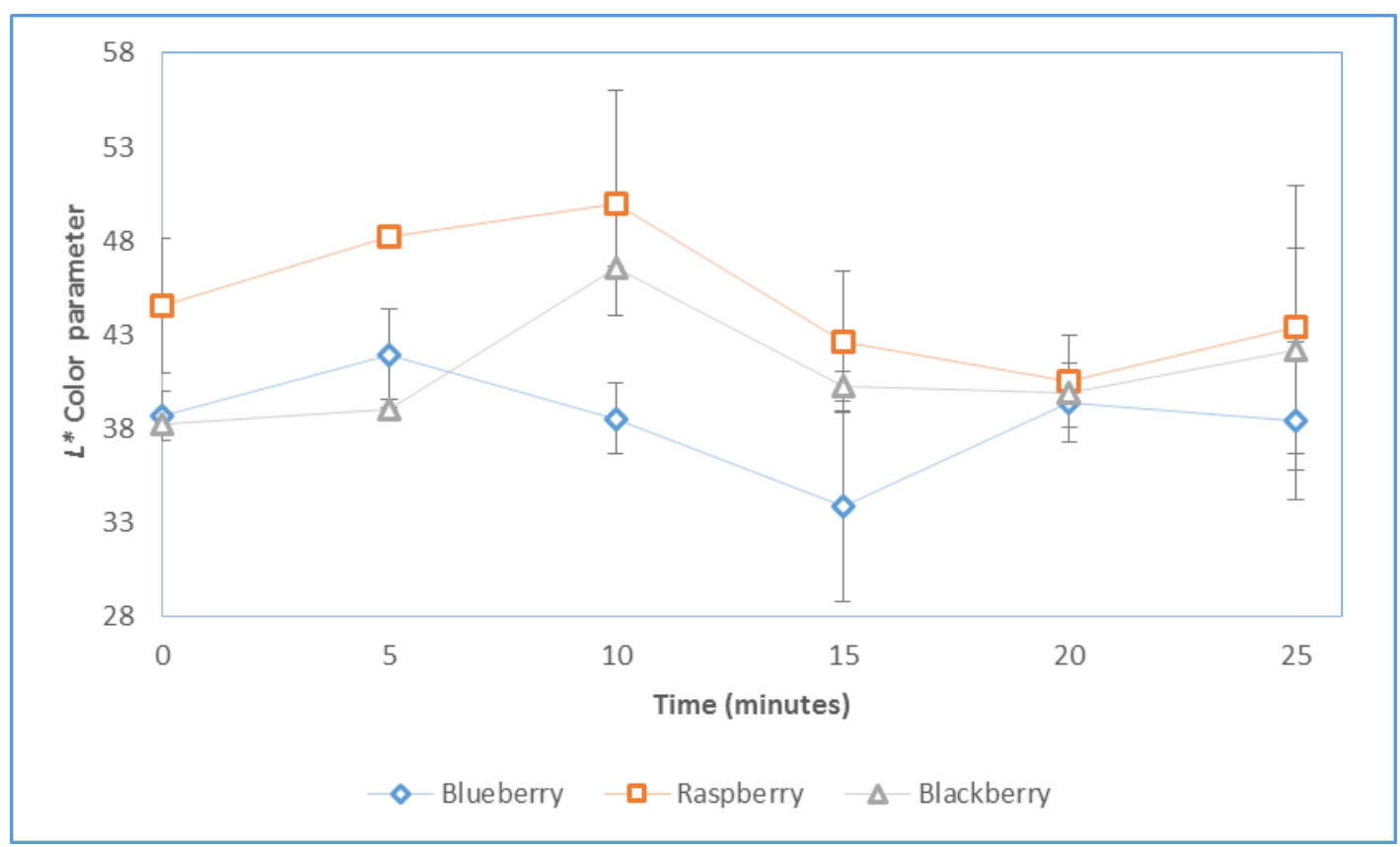

Figure 1. UV-C light effect on the $L^{*}$ color parameter of nectars of berries.

$a^{*}$ color parameter. In Figure 2 is illustrated the effect of the UV-C light on the $a^{*}$ color parameter of berries nectars. The scale of the $a^{*}$ color parameter goes from negative values (green color) to positive values (red color). Raspberry nectar showed a red color. It was observed that the UV-C light treatment had very little effect over the $a^{*}$ value. After 25 minutes of UV-C light treatment, very similar values to time 0 were found (around 5); this value indicates that the color has a tendency to red. Blueberry was in the limit between green and red (an $a^{*}$ value around one was observed) and was maintained along the UV-C light treatment (0 to $25 \mathrm{~min}$ ). Blackberry nectar had a light change after 25 minutes of UV-C light treatment; showing initially positive $a^{*}$ values (around 0.5 ) and ending with negative values (around -1). This small change in the $a^{*}$ color parameter may be due to the fact that blackberry had the greatest antioxidant capacity of the three fruits which is due to higher quantities of some phenolic and antioxidant compounds that can cause a light darkening; however, the change in color is barely modified (no detected by the eye). As mentioned above, some berries (blackberry and blueberry) have deep red-blue color due to the anthocyanins content and type. Thus, a change in the product color may mean a change in the anthocyanins content or in their chemical structure which also depend strongly on $\mathrm{pH}$. The statistical analysis indicated no significant differences ( $p>0.05$ ), within the treatment time, for all nectars treated with UV-C light. 


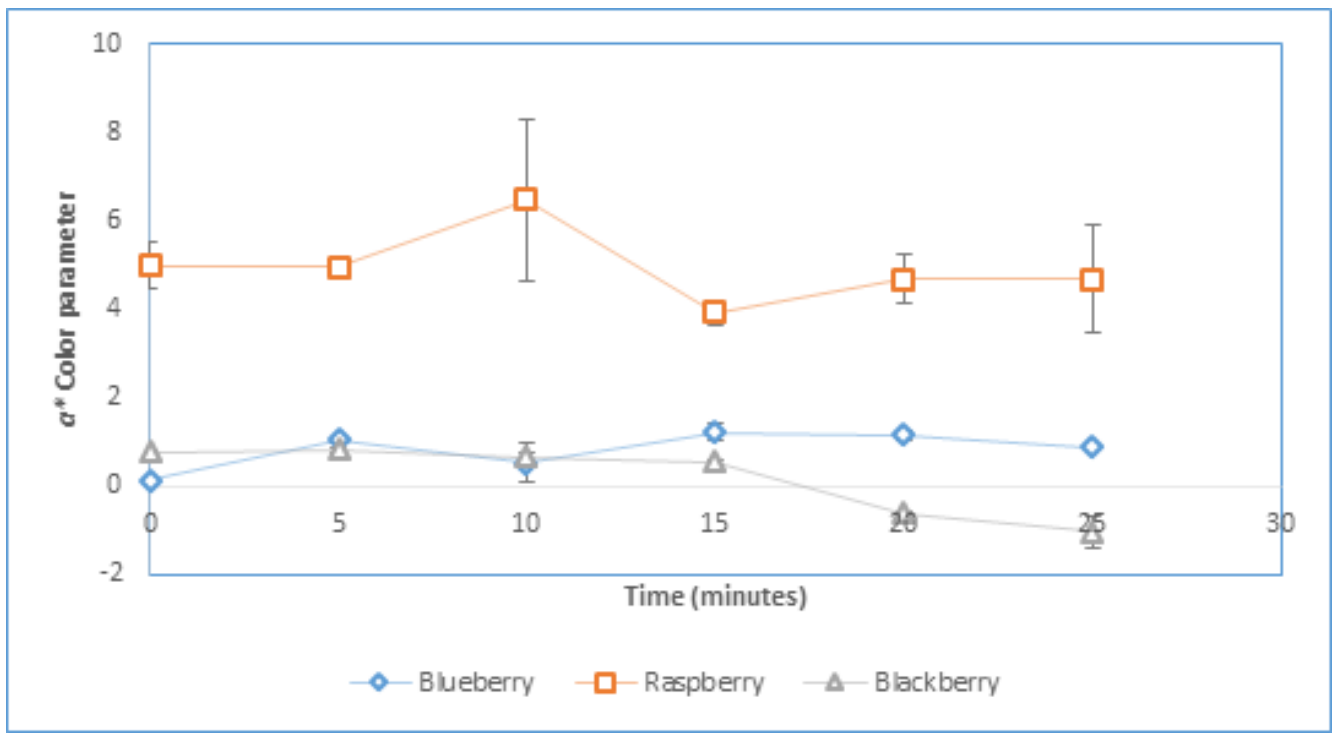

Figure 2. UV-C light effect on the $a^{*}$ color parameter of nectars of berries.

$b^{*}$ color parameter. Figure 3 shows the effect of the UV-C light treatment on the $b^{*}$ color parameter of berries nectars. The $b^{*}$ color parameter on the CIELAB scale corresponds from yellow (positive values) to blue (negative values) hues. In general, the $b^{*}$ color values were between 0.5 and 4 along the UV-C light treatment for the three nectars, being the raspberry nectar barely affected. All $b^{*}$ color values were in the limits of yellow and blue. All nectars were pale in color to the naked eye. The "highest" values (no really high) were for the raspberry nectar, meaning that the product was less bluish. The closer $b^{*}$ values to blue color were for blackberry and blueberry nectars. In general, the $b^{*}$ color parameter was not affected $(\mathrm{p}>0.05)$ within the treatment time; therefore, nectars kept their colors similar to those of untreated samples. Results obtained in this study coincide with those reported by Casati, Sánchez, Baeza, Magnani, Evelson, \& Zamora (2012); they reported $b^{*}$ color values lower than 5.6 for dark berries such as blackberry and blueberry; $b *$ values were between 3 and 5 for red berries.

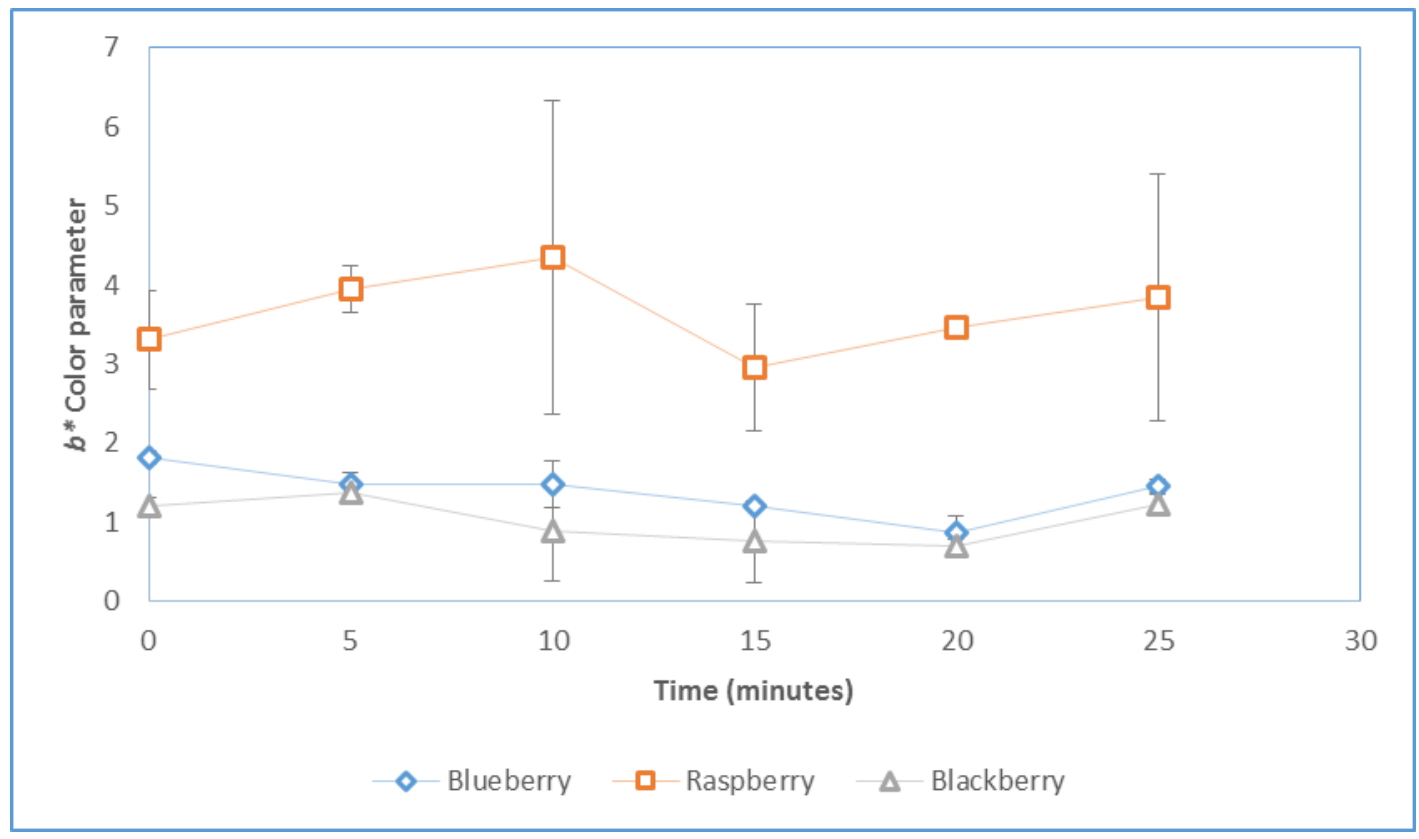

Figure 3. UV-C light effect on the $b^{*}$ color parameter of nectars of berries.

Total change in color $(\Delta \mathrm{E})$. Besides of observing low changes in the $L^{*}, a^{*}$, and $b^{*}$ color parameters, it is also important to take into account the total change in color of nectars. The $\Delta \mathrm{E}$ total change in color was $2.2 \pm 1.8$, $3.3 \pm 1.8$, and $3.3 \pm 2.9$ for blueberry, raspberry and blackberry, respectively. The less sensitive nectar to the UV-C 
light treatment was blueberry because it had the minimum $\Delta \mathrm{E}$ value. Raspberry and blackberry nectars had similar $\Delta \mathrm{E}$ values. The penetration of UV-C light depend on the color and turbidity of the liquid fruit product. Guerrero-Beltrán, Welti-Chanes, \& Barbosa-Cánovas (2009) pointed out that the UV-C light can generate changes in color, changes that could increase with the exposition time.

\subsection{Antioxidant Compounds}

\section{Antioxidant Capacity}

Figure 4 depicts the effect of UV-C light on the antioxidant capacity of berries nectars. In general, the UV-C light treatment did not affect $(\mathrm{p}>0.05)$ the antioxidant capacity within the treatment time. For blackberry, the fresh nectar showed an antioxidant capacity of $216 \mathrm{mg}$ T/100 mL. After 25 minutes of UV-C light treatment, the antioxidant capacity was $218 \mathrm{mg} \mathrm{T} / 100 \mathrm{~mL}$, which means that no UV-C light effect was observed in the antioxidant components. For blueberry something similar happened, the initial and final values were very close to each other, no reduction of antioxidant capacity was observed due to the UV-C light. According to Alothman, Bhay, \& Karim (2009), the UV-C light did not modify the antioxidant capacity of fresh-cut tropical fruits (pineapple, banana, and guava); however, those fruits have other types of pigments (carotenoids). López-Rubira, Conesa, Allende, \& Artés (2005) found similar results in pomegranate juice which also has anthocyanins as berries have. They reported that the antioxidant capacity of the pomegranate juice did not change after 30 minutes of UV-C light exposure. In raspberry nectar (light reddish), it was observed a decrease in the antioxidant capacity during the UV-C light processing; a decrease from 65 to $15 \mathrm{mg}$ T/100 mL of nectar was observed. Similar results were found by Caminiti, Palgan, Muñoz, Noci, Whyte, \& Morgan (2012) who indicated that in clear juices, such as clarified apple juice and raspberry juice, as the exposition time increased, the antioxidant capacity decreased because of a greater penetration of the UV-C light. Another important factor that can contribute to a decrease in the antioxidant capacity of raspberry nectar is the ascorbic acid content. Both, raspberry and blueberry showed a low content of ascorbic acid compared to blackberry; ascorbic acid was lessen during UV-C light treatment (Figure 7). Nevertheless, no significant differences were observed ( $p>0.05$ ) within the treatment time for the antioxidant capacity in blueberry and raspberry nectars; on the contrary in the case of raspberry nectar where significant differences were observed $(\mathrm{p}<0.05)$. Erkan, Wang, \& Wang (2008) have pointed out that the UV-C light may increase the antioxidant capacity in strawberries and some other fruits, by increasing the content of phenolic compounds naturally present in fresh fruits which has to be with phytoalexins (antimicrobials and antioxidants).

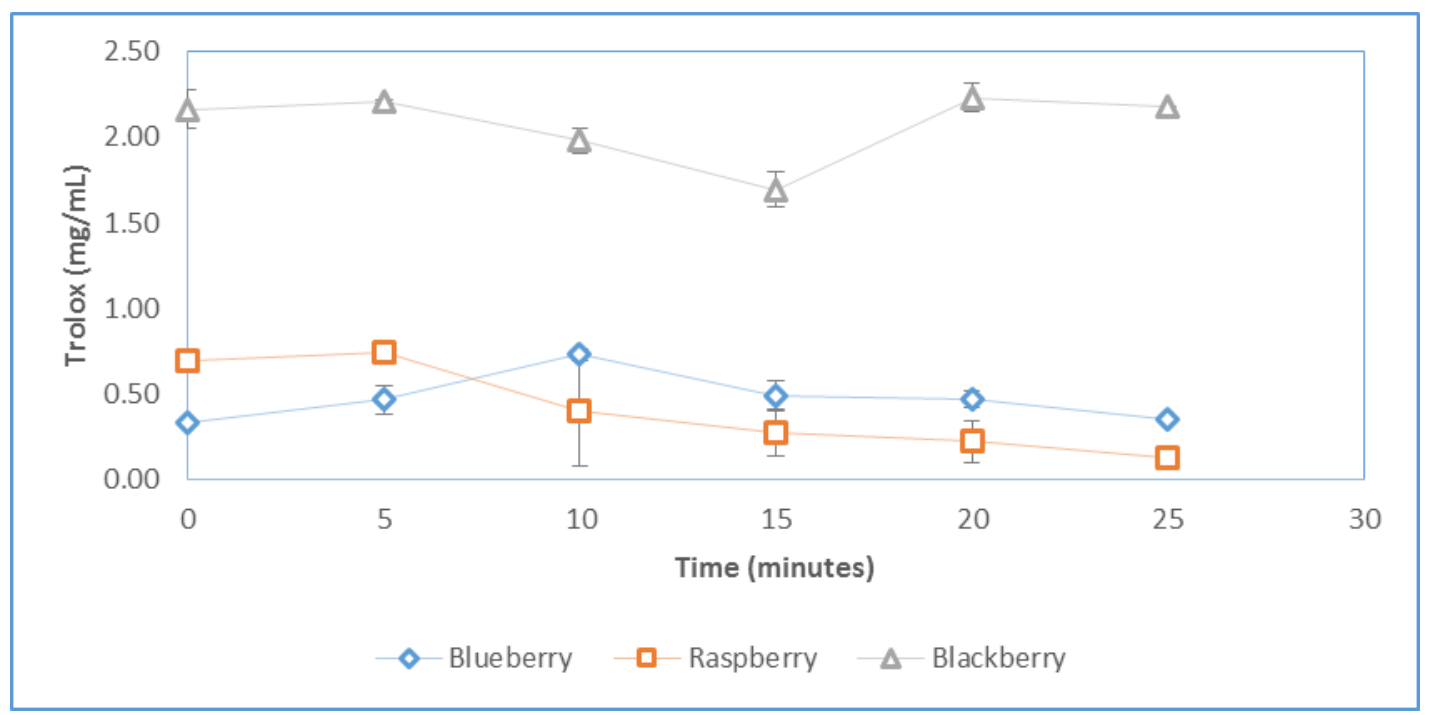

Figure 4. Effect of UV-C light on the antioxidant capacity of nectars of berries.

\section{Total Phenolic Compounds}

Figure 5 depicts the effect of the UV-C light on the total phenolic compounds (TPC) of berries nectars. Blackberry and raspberry may contain phenolic compounds such as hydroxybenzoic acids (protocatechuic, Gallic, or p-hydroxybenzoic acids) and blueberry may contain hydroxycinnamic acids (caffeic, chlorogenic, coumaric, ferulic, or sinapic) (Manach, Scalbert, Morand, Remesy, \& Jiménez, 2004). TPC slightly decreased as the treatment time increased in blueberry and raspberry nectars. TPC in blackberry nectar remained constant along the treatment, its dark color may minimize the effect of the UV-C light on phenolic compounds. The 
greater the content of dark colors the lower the penetration of the light; therefore, less effect over some compounds may occur. Ochoa-Velasco \& Guerrero-Beltrán (2012) reported that the UV-C light processing remarkably reduced the content of phenolic compounds in pitaya juice as the exposition time increased. The explanation to the reduction of pigments in fruit products is because UV-C light may affect the structures of some compounds. Pala \& Toklucu (2011) reported no significant differences ( $p>0.05$ ) in the content of phenolic compounds in pomegranate juices after UV-C light treatment; the same findings were reported by Caminiti, Palgan, Muñoz, Noci, Whyte, \& Morgan (2012) in apple juice. The nectar that was more effected on TPC by the UV-C light was the blueberry nectar; this fact can be attributed to the inactivation of phenolic such as hydroxycinnamic acids and, or flavonols (Manach, Scalbert, Morand, Remesy, \& Jiménez, 2004) found in this fruit.

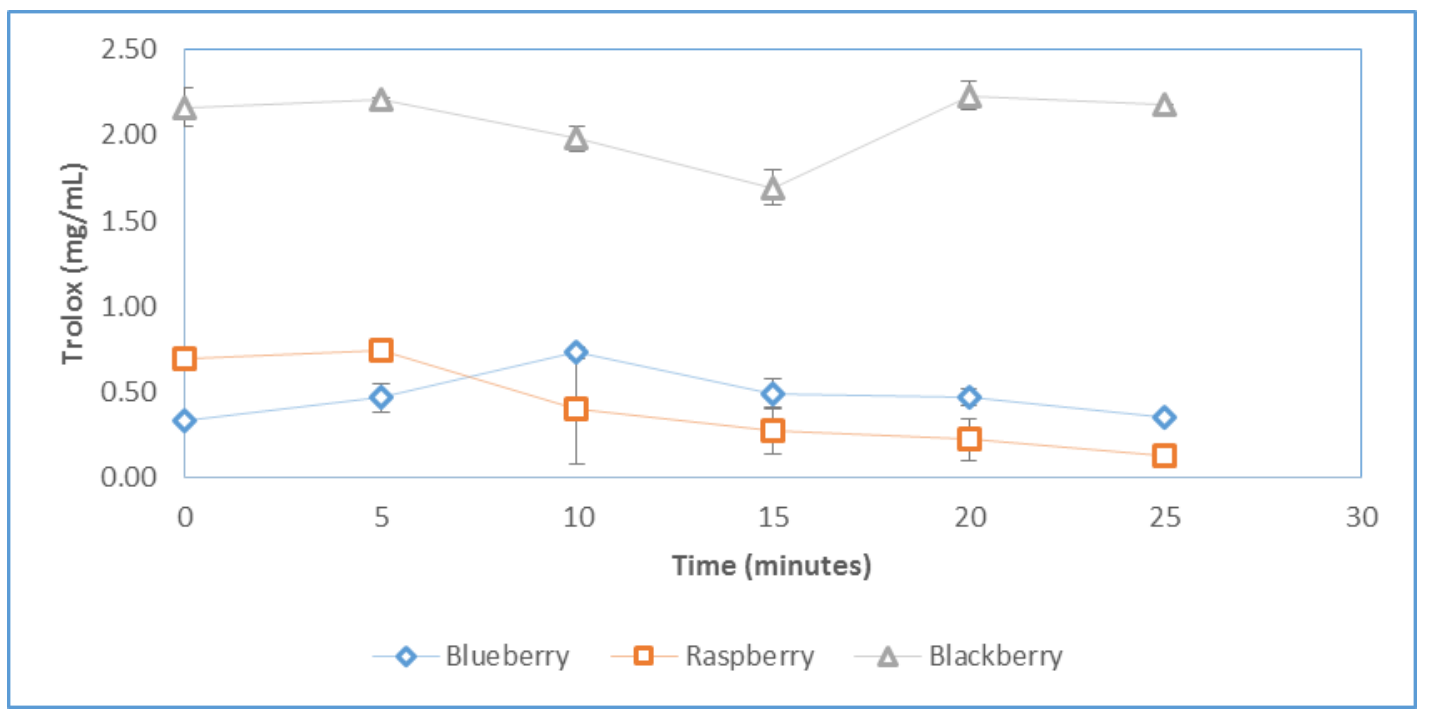

Figure 5. Effect of UV-C light on the total phenolic compounds of nectars of berries.

\section{Total monomeric anthocyanins}

Figure 6 shows the effect of the UV-C light on the total monomeric anthocyanins content in berries nectars. All these berries might have anthocyanins such cyanidin, pelargonidin, peonidin, delphinidin or malvidin (Manach, Scalbert, Morand, Remesy, \& Jiménez, 2004). The UV-C light increased significantly $(\mathrm{p}<0.05)$ the anthocyanins content in blueberry and blackberry nectars during UV-C light processing. A light decrease ( $\mathrm{p}<$ 0.05) of anthocyanins was observed in the raspberry nectar; however, not important changes were observed; actually there is not a decrease, the anthocyanins content was around $35 \mathrm{mg} / \mathrm{L}$ in average. Pala \& Toklucu (2011) have pointed out that the UV-C light does not generate changes in the anthocyanins content in pomegranate juice.

\section{Ascorbic Acid}

Figure 7 illustrates the effect of UV-C light on the ascorbic acid (AA) content in berries nectars. The AA content was significantly reduced $(p<0.05)$ in the three UV-C light treated berries nectars as the exposition time increased.

\subsection{Microbial Counts \\ Mesophilic aerobic bacteria}

Figure 8 illustrates the mesophilic aerobic bacteria (MAB) inactivation in berries nectars treated with UV-C light. As stated before, color and turbidity of the liquid food product may affect the UV-C light penetration. Dark and turbid liquid foods are less penetrated by the UV-C light, contrary to the effect on transparent and light colored liquid foods. Blackberry was turbid and had a purplish color. A maximum of 1000 colony forming units per milliliter of MAB were counted in fresh blackberry nectar. A maximum of 0.6 logarithmic cycles of MAB were reduced in blackberry nectar along the treatment time. In blueberry (turbid and bluish) and raspberry (turbid and pale reddish), reductions of 0.97 and 1.3 logarithmic cycles were achieved, respectively, after of 25 min of UV-C light treatment. The raspberry nectar showed the highest MAB reductions, very probably due to its color that favored the penetration of light. The blackberry nectar had the smallest MAB reductions due to its dark color. Lorenzini, Fracchetti, Bolla, Stefanelli, \& Rossi (2010) reported 1 - 3 logarithmic cycles reductions of MAB in UV-C light treated grape juice and red wine. Ochoa-Velasco \& Guerrero-Beltrán (2012) reported 2.11 
logarithmic reductions of MAB in pitaya (Stenocereus griseus) juice after 25 minutes of treatment with UV-C light at the same flow rate $(16.48 \mathrm{~mL} / \mathrm{s})$ used in this study.

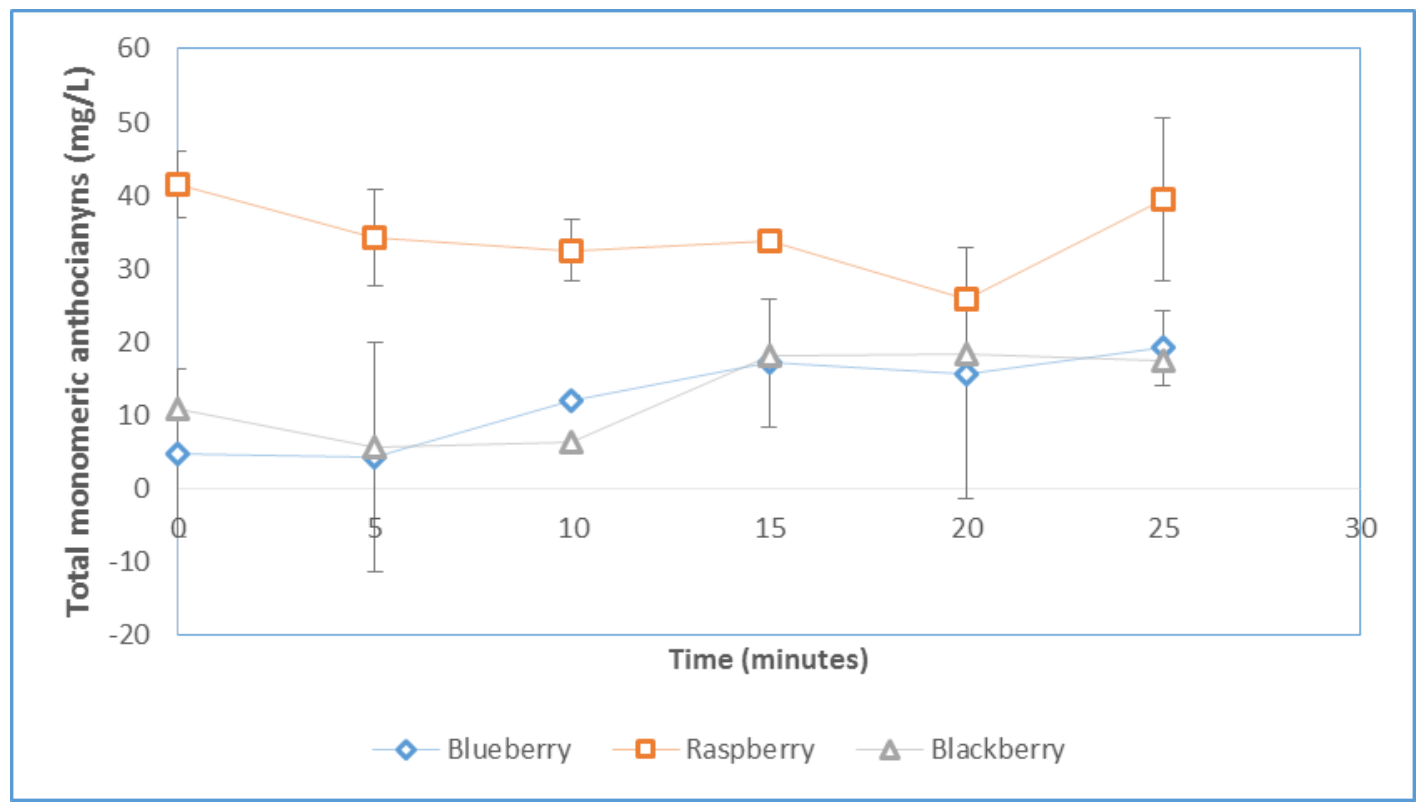

Figure 6. Effect of UV-C light on the total monomeric anthocyanins content in nectars of berries.

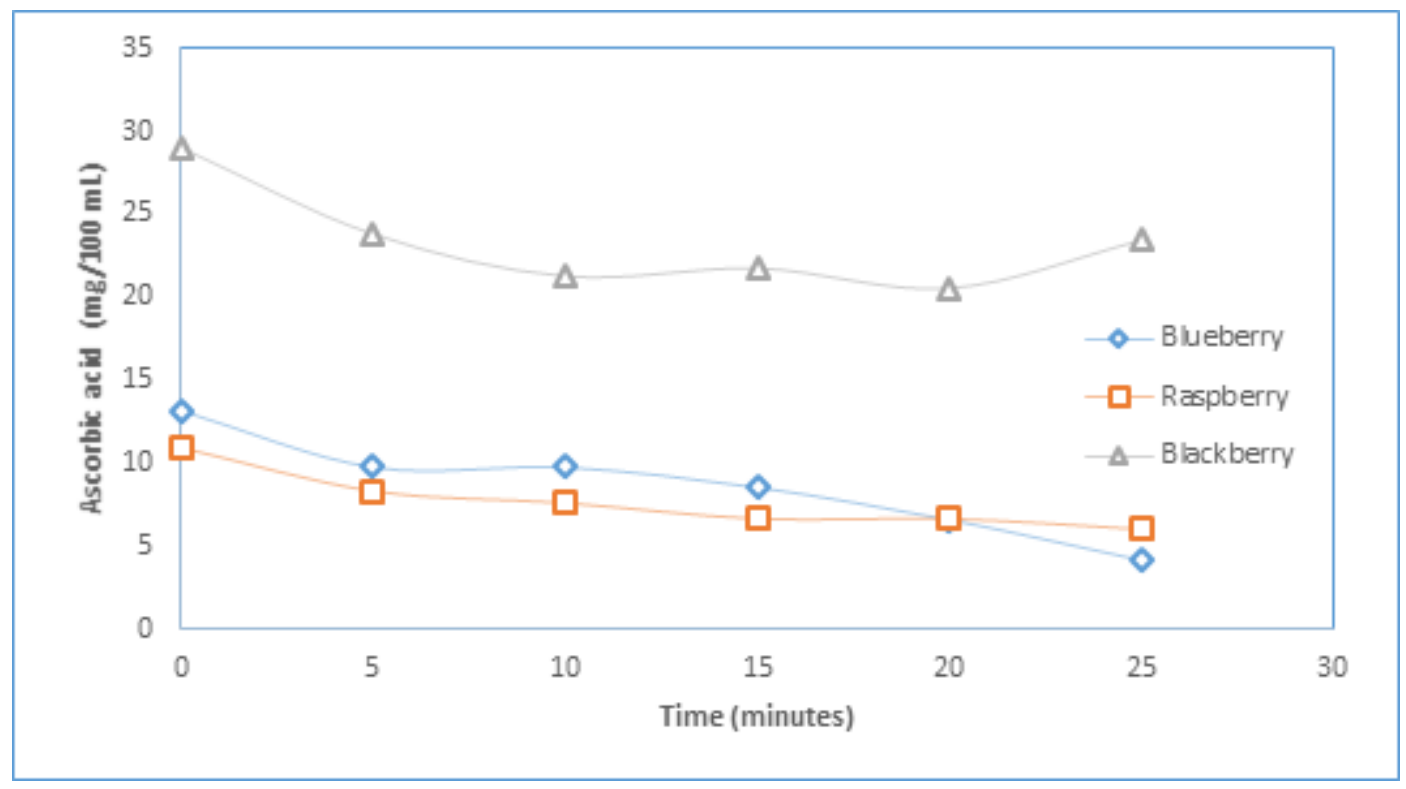

Figure 7. Effect of UV-C light on the ascorbic acid content in nectars of berries.

\section{Molds}

Figure 9 shows the effect of UV-C light treatment on the reduction of molds in berries nectars. A maximum of 100 colony forming units per milliliter of molds were counted in fresh raspberry nectar. The highest reduction of molds was achieved in the raspberry nectar; a reduction of 1.62 logarithmic cycles was observed after 25 minutes of UV-C light treatment. In blueberry nectar was observed the smallest reduction $(0.75$ logarithmic cycles) of molds after 25 min of treatment. In blackberry nectar, a reduction of 0.88 logarithmic cycles was observed. Ochoa-Velasco \& Guerrero-Beltrán (2012) reported reductions of 1.14 logarithmic cycles in pitaya juice after $30 \mathrm{~min}$ of UV-C light treatment. 


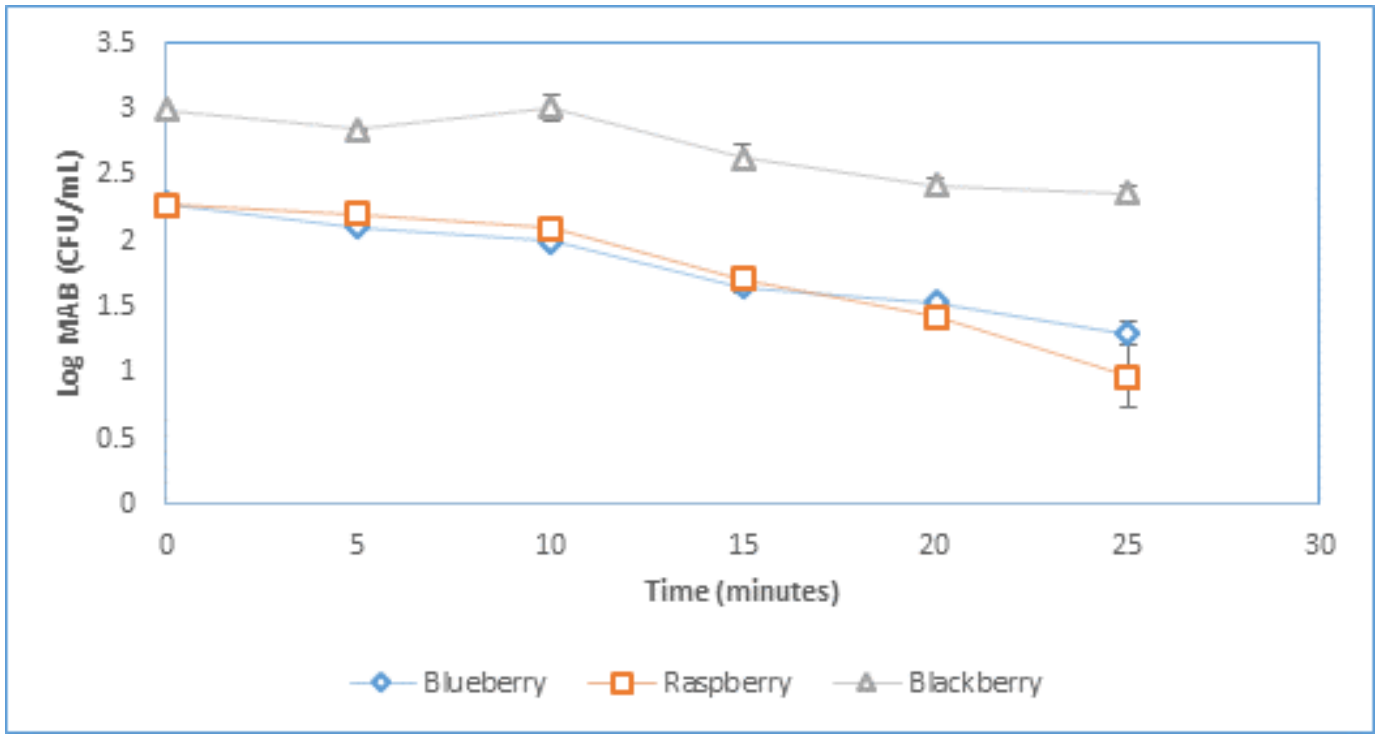

Figure 8. Effect of UV-C light on mesophilic aerobic bacteria reduction in nectars of berries.

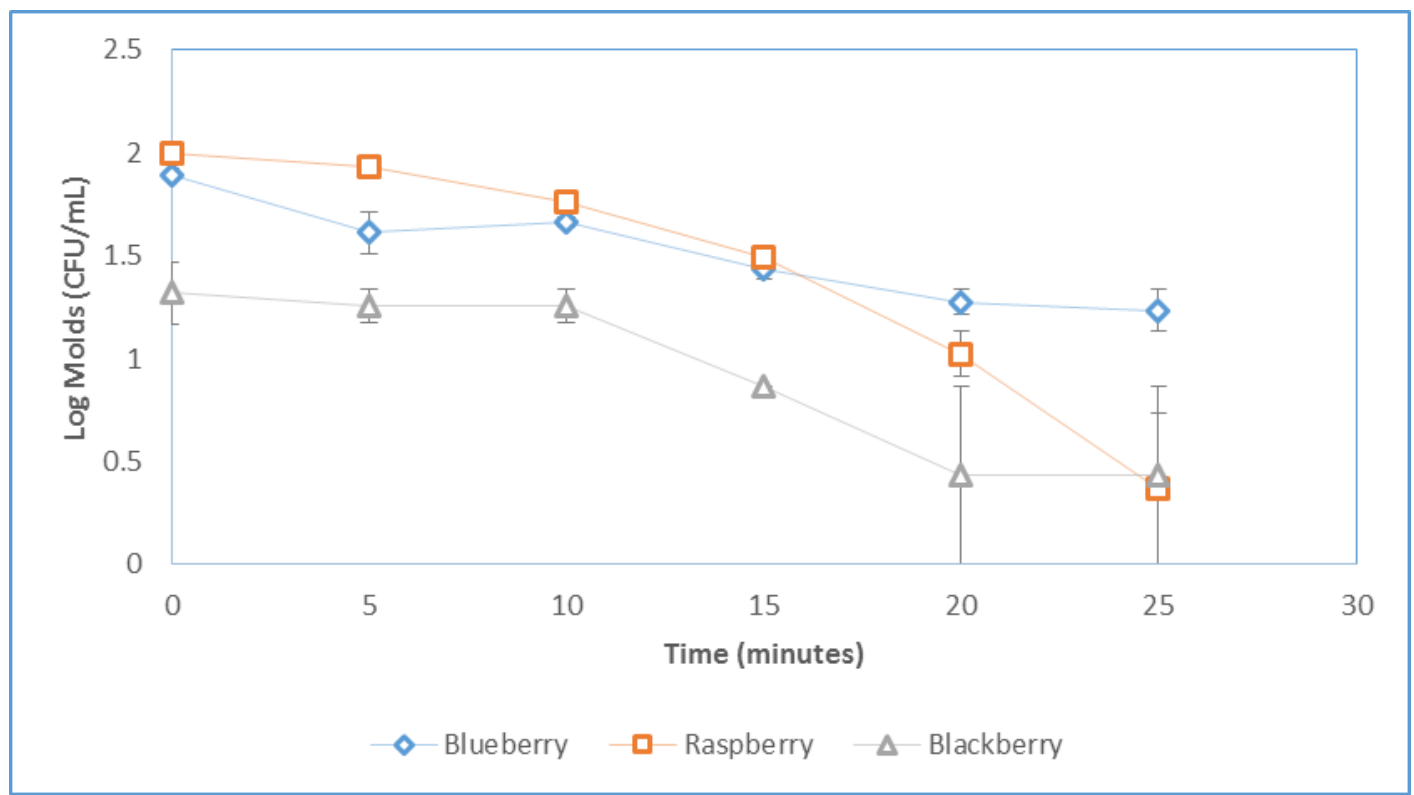

Figure 9. Effect of UV-C light on molds reduction in nectars of berries.

\section{Yeasts}

Figure 10 shows the effect of UV-C light on the reduction of yeasts in berries nectars. Reductions of $0.76,0.80$ and 2.02 logarithmic cycles of yeasts were achieved in blackberry, blueberry and raspberry nectars, respectively. Ochoa-Velasco \& Guerrero-Beltrán (2013) reported a reductions of 1.8 cycles in UV-C light treated pitaya juice. Guerrero-Beltrán, Welti-Chanes, \& Barbosa-Cánovas (2009) observed reductions of 2.5 logarithmic cycles of $S$. cerevisiae in cranberry and grapefruit juices after 30 minutes of UV-C light treatment, being those results similar to results found in this study. 


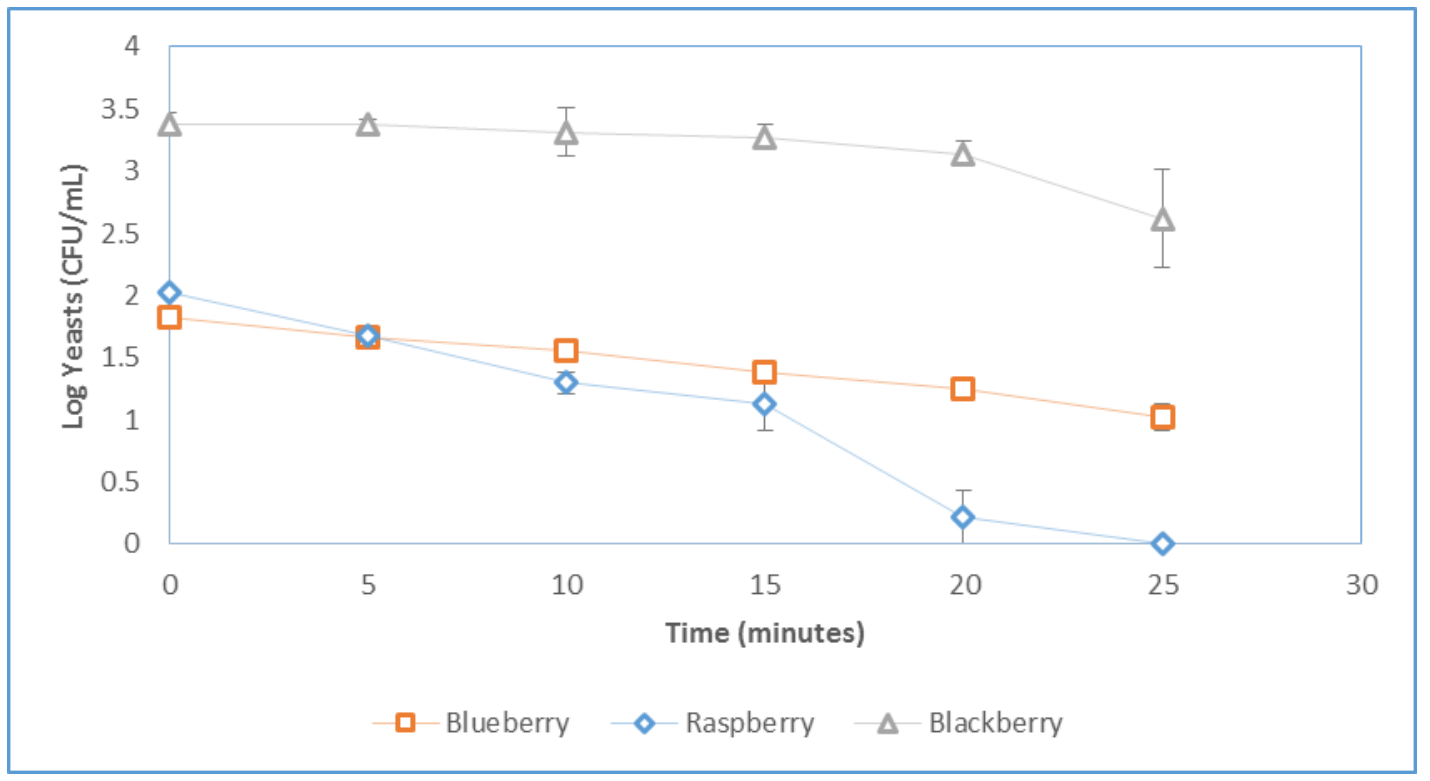

Figure 10. The Effect of UV-C light on yeasts reduction in nectars of berries.

\section{Conclusions}

According to results found in this study, it was clear that the UV-C light had no effects on pH, acidity or TSS in blueberry, raspberry, and blackberry nectars. Color parameters were affected along the treatment time differently for each type of nectar. According the $\Delta \mathrm{E}$ total change in color, the less sensitive nectar to the UV-C light was the blueberry nectar; the most sensitive to the UV-C light was the raspberry nectar. The antioxidant capacity was barely affected in the raspberry nectar. Phenolic compounds were decreased lightly in the blueberry and raspberry nectars as the UV-C light exposition time increased. The anthocyanins content increased significantly after 25 minutes of treatment in the blueberry and blackberry nectars. The ascorbic acid content in nectars was lightly lessened due to the UV-C light effect. In average, logarithmic reductions of 1.0, 1.08, and 1.19 were obtained for MAB, molds, and yeasts, respectively, in these types of nectars.

\section{Acknowledgments}

J. F. Haro-Maza would like to thanks to the Consejo Nacional de Ciencia y Tecnología (CONACYT) and the Universidad de las Américas Puebla (UDLAP) in Mexico for supporting his Mater Science degree studies.

\section{References}

Alothman, M., Bhay, R., \& Karim, A. A. (2009). UV radiation-induced changes of antioxidant capacity of fresh-cut tropical fruits. Innovative Food Science and Emerging Technologies, 10, 512-516. http://dx.doi.org/10.1016/j.ifset.2009.03.004

AOAC. (2000). Official Methods of Analysis (14th edition). Association of Official Analytical Chemists. USA.

Caminiti, I., Palgan, 1., Muñoz, A., Noci, F., Whyte, P., \& Morgan, D. (2012). The effect of ultraviolet light on microbial inactivation and quality attributes of apple juice. Food and Bioprocess Technology, 5(2), 680-686. http://dx.doi.org/10.1007/s11947-010-0365-x

Casati, C. B., Sánchez, V., Baeza, R., Magnani, N., Evelson, P., \& Zamora, C. M. (2012). Relationships between color parameters, phenolic content and sensory changes of processed blueberry, elderberry and blackcurrant commercial juices. International Journal of Food Science and Technology, 47, 1728-1736. http://dx.doi.org/10.1111/j.1365-2621.2012.03027.x

Erkan, M., Wang, S. Y., \& Wang, C. Y. (2008). Effect of UV treatment on antioxidant capacity, antioxidant enzyme capacity and decay in strawberry fruit. Postharvest Biology and Technology, 48(2), 163-171. http://dx.doi.org/10.1016/j.postharvbio.2007.09.028

FDA. (2000). Irradiation in the production, processing and handling of food. 21 CFR Part 179. Federal Register, 65(230), 71056-71058.

Fulecki, T., \& Francis, F. J. (1968). Quantitative methods for anthocyanins. Extraction and determination of total anthocyanins in cranberries. Journal of Food Science, 33, 71-77. 
http://dx.doi.org/10.1111/j.1365-2621.1968.tb00887.x

Gao, X., Ohlander, M., Jeppsson, N., Bjork, L., \& Trajkovski, V. (2000). Changes in antioxidant effects and their relationship to phytonutrients in fruits of sea Buckthorn (Hippophae rhamnoides L.) during maturation. Journal of Agricultural and Food Chemistry, 48, 1485-1490. http://dx.doi.org/10.1021/jf991072g

Gardner D. W. M., \& Shama, G. (2000). Modeling UV-C induced inactivation of microorganisms on surfaces. Journal of Food Protection, 63(1), 63-70.

Giusti, M. M., \& Wrolstad, E. R. (2000). Characterization and measurement of anthocyanins by UV-Visible spectroscopy. John Wiley \& Sons, Inc. Unit F1.2.

Guerrero-Beltrán, J. A., \& Barbosa-Cánovas, G. V. (2006). Inactivation of Saccharomyces cerevisiae and polyphenoloxidase activity in mango nectar treated with ultraviolet light. Journal of Food Protection, 69(2), 362-368.

Guerrero-Beltrán, J. A., Welti-Chanes, J., \& Barbosa-Cánovas, G. V. (2009). Ultraviolet-C light processing of grape, cranberry and grapefruit juices to inactivate Saccharomyces cerevisiae. Journal of Food Process Engineering, 32, 916-932. http://dx.doi.org/10.1111/j.1745-4530.2008.00253.x

Kuskoski, M., Asuero, A., Parrilla, M., Troncoso, A., \& Fett, R. (2004). Actividad antioxidante de pigmentos antociánicos. Ciencia y Tecnología de Alimentos (Campinas, Brasil), 24, 691-693.

López-Rubira, V., Conesa, A., Allende, A., \& Artés, F. (2005). Shelf life and overall quality of minimally processed pomegranate arils modified atmosphere packaged and treated with UV-C. Postharvest Biology and Technology, 37(2), 174-185. http://dx.doi.org/10.1016/j.postharvbio.2005.04.003

Lorenzini, F., Fracchetti, V., Bolla, E., Stefanelli, F., \& Rossi, S. (2010). Ultraviolet light irradiation as an alternative technology for the control of microorganisms in grape juice and wine. Conference: International Organization of Vine and Wine - 33rd World Congress of Vine and Wine, 8th General Assembly of the OIV, V-2010_n ${ }^{\circ}$ (1240) OR.II.19, 1-8.

Manach, C., Scalbert, A., Morand, C., Remesy, C., \& Jiménez, L. (2004). Polyphenols: food source and bioavailability. American Journal of Clinical Nutrition, 79, 727-747.

McLaren, K. (1986). The quantification of colour differences. Ch. 10. In The Colour Science of Dyes and Pigments (pp. 129-152). Bristol, Great Britain: Adam Hilger Ltd.

Ochoa-Velasco, C. E., \& Guerrero-Beltrán, J. A. (2012). Ultraviolet-C light effect on Pitaya (Stenocereus griseus) juice. Journal of Food Research, 1(2), 60-70. http://dx.doi.org/http://dx.doi.org/10.5539/jfr.v1n2p60

Ochoa-Velasco, C. E., \& Guerrero-Beltrán, J. A. (2013). Short-wave ultraviolet-C light effect on pitaya (Stenocereus griseus) juice inoculated with Zygosaccharomyces bailii. Journal of Food Engineering, 117(1), 34-41. http://dx.doi.org/10.1016/j.jfoodeng.2013.01.020

Pala, C., \& Toklucu, A. (2011). Effect of UV-C light on anthocyanin and other quality parameters of pomegranate juice. Journal of Food Composition and Analysis, 24(6), 790-795. http://dx.doi.org/10.1016/j.jfca.2011.01.003

Purgar, D. D., Duralija, B., Voca, S., Vokurka, A., \& Ericisli, S. (2012). A comparison of fruit chemical characteristics of two wild grown Rubus species from different locations of Croatia. Molecules Journal, 17, 10390-10398. http://dx.doi.org/10.3390/molecules170910390

Ribeiro, C., Canada, J., \& Alvarenga, B. (2012). Prospects of UV radiation for application in postharvest technology. Journal of Food Agriculture, 24(6), 586-597.

\section{Copyrights}

Copyright for this article is retained by the author(s), with first publication rights granted to the journal.

This is an open-access article distributed under the terms and conditions of the Creative Commons Attribution license (http://creativecommons.org/licenses/by/4.0/). 